\title{
Information, belief elicitation and threshold effects in the 5X1000 tax scheme: a framed field experiment
}

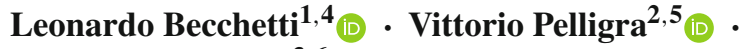 \\ Tommaso Reggiani ${ }^{3,6}$
}

\begin{abstract}
In this paper, we study by means of a framed field experiment on a representative sample of the population the effect on people's charitable giving of three, substantial and procedural, elements: information provision, belief elicitation and threshold on distribution. We frame this investigation within the 5X1000 tax scheme, a mechanism through which Italian taxpayers may choose to give a small proportion $(0.5 \%)$ of their income tax to a voluntary organization to fund its activities. We find two main results: (i) providing information or eliciting beliefs about previous donations increases the likelihood of a donation, while thresholds have no effect; (ii) information about previous funding increases donations to organizations that received fewer
\end{abstract}

Electronic supplementary material The online version of this article (doi:10.1007/s10797-017-9474-z) contains supplementary material, which is available to authorized users.

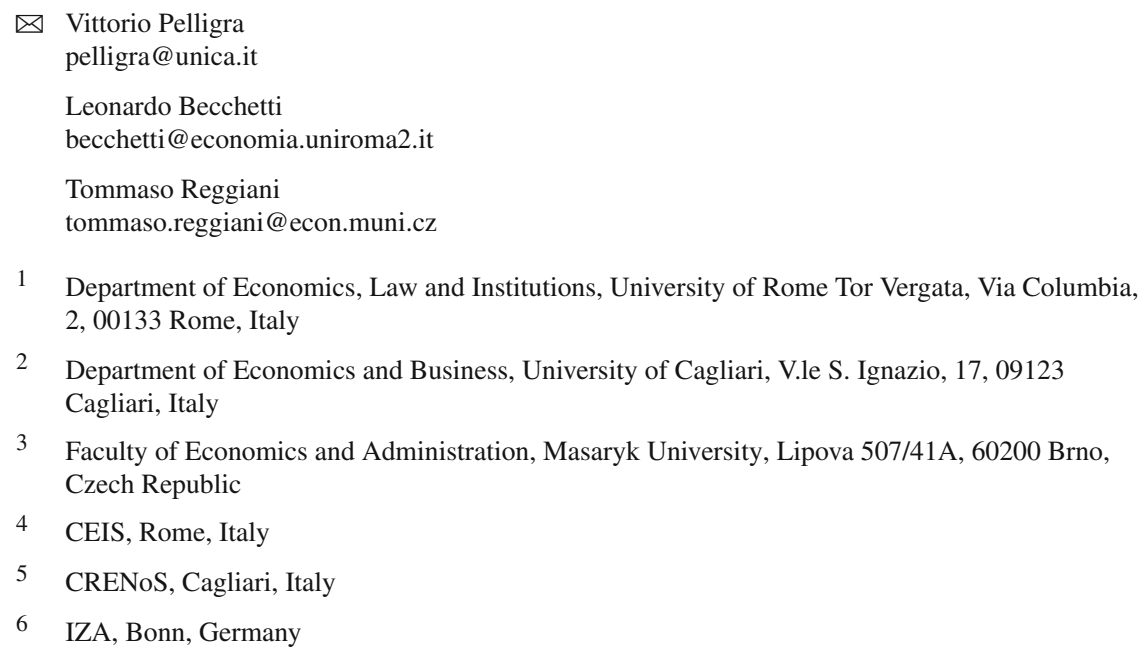


donations in the past, while belief elicitation also increases donations to organizations that received most donations in the past, since individuals are more likely to donate to the organizations they rank first.

Keywords Charitable giving · Framed field experiment - Social information effect · Inequity aversion

\section{JEL Classification C91 · D64 · H00}

\section{Introduction}

In times of tightened government budget constraints in high-income countries, the subsidiary role of not-for-profit organizations in the provision of public goods and services is becoming of paramount importance. The supply of such goods and services crucially depends on the organization's capacity to raise funds and stimulate individuals' willingness to give. It therefore becomes increasingly relevant to understand better how different funding schemes may work and which factors may affect people's willingness to give. Economists have traditionally focused their attention on the effect of changes in 'price' on giving responses. To identify the effect of 'price' changes on donations and the associated elasticity of giving is especially important from the policy-makers' perspective. Since, in fact, charitable giving favors the production of public goods that the public sector might want to encourage, donations can subsidize it by, for instance, tax deductibility, as occurs in many fiscal systems around the world. In the US, for this reason, the price of charitable giving is inversely related to the marginal tax rate that implies that those with higher incomes get higher marginal subsidies. In the UK, a similar logic applies to the payroll giving (Give as You Earn). In this system, donations are removed before income tax is calculated and deducted. The consequence is that tax is calculated on a lower amount and the deduction may lower the amount of tax to pay also by changing an individual's tax bracket.

There are fiscal systems even more generous, where the tax deductibility appears in extreme forms. The Italian 5X1000 (five by thousand), introduced in 2006, for instance, permits the taxpayers to donate each year to their preferred organization a share equal to the five per thousand of their personal income tax. In this way, the State finances the not-for-profit sector forgoing a certain amount of tax revenues and delegating to the taxpayer the control on how to allocate this public fund among the different organizations. This represents an extreme form of 'price' reduction with the actual price set equal to 0 .

The efficacy of these systems in stimulating private funding depends on how taxpayers and other potential donors respond to the formal, informal and social incentives they provide. In this respect, one such element that both economists and psychologists have recently focused on is social information: how information about other people's contributions affects individuals' willingness to fund charities and public goods more in general. ${ }^{1}$ In general, we may think of two types of influences of social information:

\footnotetext{
1 See Andreoni (2006) and Vesterlund (2006) for economics-oriented reviews and Cialdini and Goldstein (2004); Penner et al. (2005); Weber et al. (2004) for reviews about contributions from psychology.
} 
a "substitution effect" and a "complementarity effect." The former is consistent with models of altruistic behavior (Becker 1974; Warr 1982; Roberts 1984; Andreoni 1988, 1990): the more other people (or institutions) give, the less the individual is motivated to contribute. The second effect is implied by models of reciprocity (Sugden 1984), conformity (Bernheim 1994), signaling (Vesterlund 2003), social image (Benabou and Tirole 2006; Andreoni and Bernheim 2009; Ellingsen and Johannesson 2007, 2008) and social connection (Scharf 2014). They all predict that knowing people are giving stimulates other people's donations.

Empirical evidence has been, so far, largely inconclusive, providing support to both effects: Andreoni (2006); Powell and Steinberg (2006) and Kolm and Ythier (2006) review a number of empirical studies concluding that, apart from complete crowding-out, none of the other predictions (complementarity or substitutability) can be disconfirmed. Data from laboratory experiments (see Shang and Croson (2009) for a survey) are generally supportive of the positive effect of social information, but the robustness of these results has been variously criticized, mainly because of weaknesses in the experimental designs and on the questionable external validity of their conclusions. Few studies have tried to overcome such criticisms by adopting more convincing treatment manipulations and considering non-conventional subject pools. In one of these, Frey and Meier (2004) conduct a natural field experiment with all the students of the University of Zurich. They collect data supporting the complementarity prediction, as they find that, on average, people contribute more often to a charity if they know that many others contribute. While this study is focused on the willingness to contribute or not, to a public good, Shang and Croson (2009) examine the effect that information about the amount of others' donation may have on the amount of participants' contribution. This study is fielded in the context of a fundraising campaign for a public radio and finds a positive and significant relationship between social information and the amount given.

We contribute to this growing literature by focusing on the effect of three, substantial and procedural, elements: social information, belief elicitation and the imposition of an exogenous threshold on total contribution. We study both the impact of these elements on individuals' willingness to donate and also how they affect the distribution of donations among a set of different organizations. We investigate these elements by means of a framed field experiment involving a representative pool of the population. We frame the experiment considering the '5X1000 tax scheme', a mechanism through which Italian taxpayers may choose to give a small proportion of their income tax to a voluntary organization to fund its activities. The design and the hypotheses of our experiment are motivated, as we said, by an interest in the role of information in charitable giving and its policy implications, but also by the heated debate among policy-makers and practitioners fueled by different positions about the role of publicsocial information, which is accompanying in these years, the experimentation of the 5X1000 mechanism and the discussion about the pros and cons of its implementation.

In its basic form, this mechanism allows taxpayers to divert, each year, a small share (equal to the five per thousand) of their personal income tax from the State 
to one among not-for-profit organizations active in the production of public goods. ${ }^{2}$ Through this channel, the State finances the "third sector" forgoing a certain amount of tax revenues and delegating to the taxpayer the control on how to allocate this portion of public funds among the different organizations and their preferential ends.

In the recent years, however, the implementation of the 5X1000 mechanism has been criticized on two main points: first, the neglect of the role of information about each organization's funding results. Data about how much each of them received in the previous years, in fact, have not been made available on a regular basis. Many argue that knowing these data is crucial to a well-informed choice and that they may have important consequences on the allocation of funds. First, they may impact on the decision to donate. Secondly, if we assume that people not only care about the total amount distributed to the organizations but also about how these funds are allocated among the organizations, knowledge about the previous allocations of funds may lead taxpayers to choose to redistribute from the top organizations to the bottom, if they like pluralism and diversity or they aim at maximizing the impact of their single donations. On the contrary, one may hypothesize that the same information induces people to give more to the top organizations. In fact, if donors interpret giving from other taxpayers as signal of quality, for instance, they may want to reward and make even stronger the best performing organizations.

The second reason of debate refers to the decision by the Ministry of Finance to impose an upper limit to the total amount to be actually distributed. In other words, each year the Ministry of Finance establishes the maximum amount to be distributed, irrespectively of the actual amount gathered from taxpayers' choices. If total donations exceed the threshold set for a given year, only a fraction of each donation will be distributed, to a sum equal to the fixed threshold.

A third issue that we focus on refers to the role of donors' prior beliefs. Social psychologists documented that being asked to explicitly state one's beliefs may, in different context, affect subject's choices who, in an attempt to achieve consistency may modify their intended behavior (Cialdini 1984). Economists have both theoretically and experimentally studied this 'taste for consistency' and found that it is a powerful determinant of behavior (Yariv 2005; JohanssonSvedsater 2008; Falk and Zimmermann 2013). We study this 'belief elicitation effect' and its consequences on giving. More specifically, we test whether simply asking to formulate beliefs about how each organization ranked in terms of aggregate donations produces significant changes in donors' behavior. We also estimate whether participants' beliefs are systematically biased. Such bias in fact may lead to a change in giving behavior when information about the real figures is provided.

We find six main results with respect both to the probability to give and to the donations' distribution. First, when information about the previous year's aggregate donations received by each organization is provided, the probability to donate becomes significantly higher (from 90 to $96 \%$ ) with respect to when information is not available.

\footnotetext{
2 More specifically are eligible to receive donations all the voluntary organizations and other foundations and organizations (public or private) operating in the fields of scientific research, higher education, public health (including non-professional sport associations), cultural promotion and environmental protection that ask to be included in an official list maintained by the tax authority.
} 
Second, we find that the belief elicitation procedure (making the ranking salient) increases significantly the probability to donate as well (from 90 to $97 \%$ ). Third, the imposition of the threshold to the amount to be distributed decreases significantly the relative probability to donate by about 5 percentage points. The fourth finding refers to the distributive effect of the information provision. When the amount of funds received by each organization in the previous year is made known, we observe a statistically significant redistribution from the top organizations toward those at the bottom. Fifth, although participants' beliefs are systematically inaccurate, the elicitation process leads to a statistically significant increase in the contribution to the best performing organizations. Finally, we find that the imposition of the threshold up to the beliefs elicitation does not have any significant redistributive effects.

The remainder of the paper proceeds as follows. The next section describes the experimental design, the hypotheses and the procedures. Section 3 summarizes our findings. Section 4 concludes.

\section{The experiment}

\subsection{Design}

Our framed field experiment is designed to investigate the effect of information disclosure, beliefs elicitation and the imposition of an exogenous threshold on charitable giving in a large and representative sample of the population. The baseline experimental task is a modified version of the 'generosity game' (Güth 2010; Güth et al. 2012) in which all the experimental subjects play the role of the dictator, while the recipient is a real not-for-profit organization. Each dictator receives a lottery ticket and has to decide whether and to whom to donate (by selecting one organization from a list of nine provided by the experimenters $)^{3}$ the monetary prize (€ 1000) in the event of winning the lottery (see Sect. 2.3 for more details). The dictator can as well decide not to donate, but, in that case, the share of the pie going to the dictator is set equal to 0 . We consider this game instead of the more common dictator game, in order to mimic as closely as possible the real decision faced by the taxpayers in the $5 \times 1000$ mechanism. Not giving, in fact, does not increase the taxpayer wealth. If they opt not to give through the 5X1000 mechanism, the entire amount of their taxes will be retained by the State. In standard laboratory experiments, participants usually receive a monetary endowment at the beginning of the experiment like "manna from heaven"; this introduces an element of unrealism that has been repeatedly criticized. In our design, on the contrary, reality and the simulated situation are much more closely related since both taxpayers and participants decide to donate "out of pocket" money

\footnotetext{
3 The list of organizations eligible for the $5 \times 1000$ contribution includes about 50 thousand entries (year 2016). We considered a selection of the most well-known among those that operate nationwide. We tried to diversify both in terms of total amount received and mission of the organization. We included, in alphabetical order: ADMO - Bone Marrow Donors Association, Amnesty International (Italian Section), Caritas, Emergency, Banco Alimentare Onlus, Greenpeace, L.A.V. Lega Anti-Vivisezione, UNICEF (Italian Section) and $W W F$ - World Wildlife Foundation Italy. For a detailed description of the organizations, see Online Supplementary Material.
} 
Table 1 Experimental design: treatments and comparisons

\begin{tabular}{llc}
\hline Treatment & Treatment variable & Comparisons (effect) \\
\hline $\begin{array}{ll}\text { NoInfoT } \\
\text { InfoT }\end{array}$ & - & Control group \\
& Information & $\begin{array}{c}\text { InfoT versus NoInfoT } \\
\text { (information effect) }\end{array}$ \\
BeliefT & Beliefs elicitation & BeliefT versus \\
& & NoInfoT (belief \\
& & effect) \\
Belief\&ThresholdT & Beliefs elicitation + Threshold & Belief\&ThresholdT \\
& & versus BeliefT \\
& & (threshold effect) \\
\hline
\end{tabular}

that in any case would not go back to them in case of a decision not to donate. This close resemblance between experimental procedure and real-life choice increases, we think, the external validity of our design.

The game is played in a between-subject design, in four different treatments (Table 1). In the first, "No Information Treatment" (NoInfoT), subjects play the baseline game with no additional information (see Appendix A for the instructions). In the second, "Information Treatment" (InfoT), players are given information about the donations received by each of the nine organizations in the previous fiscal year through the 5X1000 mechanism. In the third, "No Information plus Belief Elicitation Treatment" (BeliefT), players have no information but they are asked to rank the organizations according to their beliefs about the amount of donations received in the previous year through the $5 \mathrm{X} 1000$ mechanism. Beliefs are elicited at the same moment the donation choice is done as is clear from the attached questionnaire where beliefs and donations choices appear as right and left columns of the same line (Appendix A). Beliefs are not incentivized. In the fourth, "No Information plus Belief Elicitation and Threshold Treatment" (Belief\&ThresholdT), players are not given information, are asked their beliefs and their choices are subject to a threshold. More specifically participants are told that, if the aggregate amount of contributions donated to all the organizations passes a maximum, unspecified, amount, each organization will receive only a percent of the amount actually donated to it. This feature of our design is aimed at reproducing the actual threshold mechanism existing in the Italian 5X1000 donation system where, if total donations exceed the threshold imposed each year by the Ministry of Finance, only a proportional fraction of each donation is actually distributed, up to a sum equal to the maximum fixed amount. In the experiment, the threshold is unspecified because in the real system, the total amount to be distributed each year is decided by the Ministry of Finance ex-post, after each taxpayer has already taken the decision whether to give or not.

We implemented an incentive system similar to that used by Fong and Luttmer (2011) and Pelligra and Stanca (2013) which is particularly suited for experiments with large sample of subjects. We gave to each respondent a lottery ticket. Once all the choices were collected, one of the tickets was randomly drawn and the choices that the owner of that ticket made determined both the actual payments ( $€ 1000$ or nothing) 
and eventually the recipient (the selected organization). The participant, as well as the organization, was then contacted by SmartLab, the market research firm that fielded the research, ${ }^{4}$ and informed about the result of the lottery and, in the case of the organization, paid by bank transfer. We ensured anonymity using a system of unique codes to identify the donors whose identity remained unknown to the experimenters. The participants do not know the total number of the interviewees; therefore, they cannot infer the probability of being selected to be paid for real. The different stages of the lottery were filmed and made available to all participants upon request. In the context of our experiment, this two-stage procedure was easier to implement than the usual one-stage random lottery incentive system, while ensuring, we think, the necessary salience.

\subsection{Hypotheses}

From our design, we can infer a series of testable hypotheses. First, let $S(g)_{T}$ denote the share of players who give, and $S(n g)_{T}$ the share of players who decide not to give in treatment

$T=\{$ InfoT, NoInfoT, BeliefT, Belief\&ThresholdT $\}$; similarly, let $G_{j T}$ denote the total amount of donations received by the organization $j$ in treatment $T$.

The hypotheses we test refer to the effect of the information disclosure, the beliefs elicitation and the introduction of the threshold both on the probability of giving (hypotheses $a$ ) and on the distribution of the donations (hypotheses $b$ ).

Hypothesis 1a (information effect on probability of giving)

$\mathrm{H}_{0}: S_{(\text {NoInfoT })}=S_{(\text {InfoT })}$

$\underline{\mathrm{H}_{\mathrm{A}}: S_{(\text {NoInfoT })} \neq S_{(\text {InfoT })}}$
Hypothesis $1 \mathrm{~b}$ (information effect on the distribution)

$\mathrm{H}_{0}: \mathrm{G}_{j(\text { NoInfoT })}=\mathrm{G}_{j(\text { InfoT })}$

$\mathrm{H}_{\mathrm{A}}: \mathrm{G}_{j(\text { NoInfoT })} \neq \mathrm{G}_{j(\text { InfoT })}$

The goal of these hypotheses is to investigate the effect on charitable behavior of the information about the total amount of funds raised by each organization in the previous year. To this end, we compare the share of givers and their preferred organizations in the "Information" and in the "No information" treatments. Under the null hypothesis, the information has no effects.

Hypothesis 2a (belief effect on probability of giving)

$\mathrm{H}_{0}: S_{(\text {NoInfoT })}=S_{j(\text { Belief } T)}$

$\underline{\mathrm{H}_{\mathrm{A}}}: S_{(\text {NoInfoT })} \neq S_{j(\text { Belief } T)}$
Hypothesis $2 \mathrm{~b}$ (belief effect on the distribution)

$\mathrm{H}_{0}: \mathrm{G}_{j(\text { NoInfoT })}=\mathrm{G}_{j(\text { Belief } T)}$

$\mathrm{H}_{\mathrm{A}}: G_{j(\text { NoInfoT })} \neq \mathrm{G}_{j(\text { Belief } T)}$

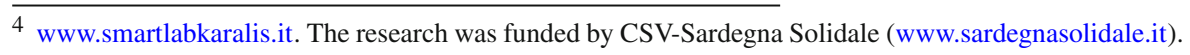


The goal of these hypotheses is to test the effect on charitable behavior and its distribution of the elicitation of prior beliefs about the donations received. Under the null hypothesis, prior beliefs have no effects.

\begin{tabular}{|c|c|}
\hline $\begin{array}{l}\text { Hypothesis } 3 \mathrm{a} \text { (threshold effect on probability } \\
\text { of giving) }\end{array}$ & $\begin{array}{l}\text { Hypothesis } 3 b \text { (threshold effect on the distri- } \\
\text { bution) }\end{array}$ \\
\hline $\mathrm{H}_{0}: S_{(\text {BeliefT })}=S_{j(\text { Belief \&ThresholdT })}$ & $\mathrm{H}_{0}: \mathrm{G}_{j(\text { Belief } T)}=\mathrm{G}_{j(\text { Belief \&ThresholdT })}$ \\
\hline $\mathrm{H}_{\mathrm{A}}: S_{(\text {Belief } T)} \neq S_{j(\text { Belief \& ThresholdT })}$ & $\mathrm{H}_{\mathrm{A}}: \mathrm{G}_{j(\text { BeliefT })} \neq \mathrm{G}_{j(\text { Belief\&ThresholdT })}$ \\
\hline
\end{tabular}

With this hypothesis, we test whether imposing a threshold on the actual distribution of the total donations given by the contributors affects the probability to donate. Under the null hypothesis, the threshold has no effects.

\subsection{Procedures}

The experiment was conducted in August-September 2013 using a representative sample of 2,000 adults stratified by gender, age and education. Subjects responded to a questionnaire carried out in Sardinia, an autonomous region of Italy, using the PAPI (paper-and-pencil interviewing) technique. In addition to a series of questions on sociodemographic characteristics, values, beliefs and pro-social activities, we included the choice task described in the previous section. ${ }^{5}$

Participants are contacted by the interviewers at home and invited to participate in a simple experimental study conducted by the University of Cagliari. They receive a self-explaining anonymous questionnaire that is completed autonomously without any intervention from the interviewer. After answering questions about socio-demographic characteristics, each participant is informed about the rules of the choice task, the consequences of her choices and the functioning of the incentive system. They are then presented with the task, and their understanding of the game is checked by a series of control questions. After completing the choice task, they answer the remaining sections of the survey. Completing the entire questionnaire takes on average about 20 minutes.

The main benefits of using a representative sample of the population (see Table 2 for the sample structure), instead of the usual convenience pool of student subjects, are relative to the sample size and to the heterogeneity and representativeness of subjects whose choices are observed. These factors have obvious pros in terms of a finer understanding of the mechanism underlying decision-making, since we have a larger number of socio-demographic determinants to which we can relate variations in behavior, but also in terms of external validity and generalizability of the experimental results.

\footnotetext{
5 The instructions and are provided in Appendix A, and the questionnaire is available in Online Supplementary Materials.
} 
Table 2 Sample structure. Source: ISTAT

\begin{tabular}{llll}
\hline & Survey sample $(\%)$ & $\begin{array}{l}\text { Survey population } \\
\text { (Sardinia) }(\%)\end{array}$ & $\begin{array}{l}\text { National population } \\
\text { (Italy) }(\%)\end{array}$ \\
\hline Age & & & \\
$15-29$ & 23.56 & 17.35 & 17.56 \\
$30-44$ & 26.90 & 23.24 & 23.40 \\
$45-59$ & 23.27 & 26.13 & 26.67 \\
60 and above & 26.27 & 33.28 & 32.34 \\
Gender & & & 48.60 \\
Male & 46.90 & 49.00 & 51.40 \\
Female & 53.10 & 51.00 & \\
\hline
\end{tabular}

Columns 2-4 refer to the survey sample, Sardinia (survey population) and Italy, respectively

Table 3 Completed questionnaires, gender and choices (by treatment)

\begin{tabular}{|c|c|c|c|c|c|c|c|}
\hline Treatment & $\begin{array}{l}\text { Subjects } \\
\text { selected }\end{array}$ & $\begin{array}{l}\text { Subjects } \\
\text { participating }\end{array}$ & $\begin{array}{l}\text { Subjects } \\
\text { complying }\end{array}$ & Male & Female & No Donation & Donation \\
\hline NoInfoT & 500 & 388 & 388 & $\begin{array}{l}175 \\
(45 \%)\end{array}$ & $\begin{array}{l}213 \\
(55 \%)\end{array}$ & $\begin{array}{l}38 \\
(9.7 \%)\end{array}$ & $\begin{array}{l}350 \\
(90.2 \%)\end{array}$ \\
\hline InfoT & 500 & 405 & 405 & $\begin{array}{l}180 \\
(44.5 \%)\end{array}$ & $\begin{array}{l}225 \\
(55.5 \%)\end{array}$ & $\begin{array}{l}15 \\
(3.7 \%)\end{array}$ & $\begin{array}{l}390 \\
(96.3 \%)\end{array}$ \\
\hline BeliefT & 500 & 346 & 250 & $\begin{array}{l}119 \\
(47.4 \%)\end{array}$ & $\begin{array}{l}131 \\
(52.6 \%)\end{array}$ & $\begin{array}{l}7 \\
(2.8 \%)\end{array}$ & $\begin{array}{l}243 \\
(97.2 \%)\end{array}$ \\
\hline \multirow[t]{2}{*}{ Belief\&ThresholdT } & 500 & 266 & 148 & $\begin{array}{l}82 \\
(55.4 \%)\end{array}$ & $\begin{array}{l}66 \\
(44.6 \%)\end{array}$ & $\begin{array}{l}13 \\
(8.8 \%)\end{array}$ & $\begin{array}{l}135 \\
(91.2 \%)\end{array}$ \\
\hline & 2000 & 1405 & 1191 & 556 & 635 & 73 & 1118 \\
\hline
\end{tabular}

Once all the questionnaires were collected, we run the lottery that determined the organization to be paid. At this stage, both the chosen participant and the organization were informed of the result.

\section{Results}

We contacted 2000 subjects and about $75 \%$ of them consented to participate in the study. Overall, we obtained 1405 questionnaires of which 214 have been excluded because - in the two treatments featured by beliefs elicitation-reported beliefs were incomplete or missing. This brings the sample to a total of 1191 compliers $^{6}$ (Table 3).

\footnotetext{
6 It is plausible to assume that non-compliance (in this case formal incompleteness of the ranking provided by the subjects) is a signal for actual non-exposition to the treatments (BeliefT and Belief\&ThresholdT). This could be due to inattention in answering the survey (skipping the page) or to an inadequate level of effort exerted in order to properly understand and process the requested ranking task. These considerations lead us to prudentially ground our analysis on information generated only by compliers.
} 
Descriptive findings document that our sample is almost perfectly balanced in terms of gender (53\% females), with average age being 45 . Respondents live in households with 2.2 members on average and around $46 \%$ of them are married. Non-donors ${ }^{7}$ are $6 \%$ in the overall sample. This share remains very low also if we look at it in the four different treatments (highest at $9.7 \%$ in the NoInfoT and lowest at $2.8 \%$ in the BeliefT) (see Table 4).

\subsection{Treatment effect on the probability to donate}

Figure 1 depicts the empirical distribution of donation across the nine organizations taken into consideration. The first outcome of interest is represented by the effect of the different treatments on the probability to generate an actual donation (hypotheses 1a, $2 \mathrm{a}$ and $3 \mathrm{a})$.

Table 5 (model 1$)^{8}$ displays estimations based on an intuitive OLS linear probability model in which the outcome dummy variable donation ( $1=$ donation, $0=$ non-donation) is regressed on treatment dummies InfoT, BeliefT, Belief\&ThresholdT. The baseline treatment NoInfoT is omitted for collinearity reasons, and it is captured in the constant term. The average donation rate under the baseline treatment is $90 \%$. InfoT has a positive and significant effect on the probability to make the donation. It increases the probability to donate by 7 percentage points (in relative terms, propensity to donate increases by $8 \%$ ). BeliefT has a positive and significant effect on the probability to make the donation. It increases the probability to donate by 6 percentage points (in relative terms, the pool of donors increased by 7\%). Belief\&ThresholdT combines together beliefs elicitation (Belief) and a threshold rule (Threshold). The coefficient for this treatment is very small (1 percentage point) and not statistically significant at any conventional level. This means that the introduction of a threshold rule neutralizes $(-5$ percentage points, $p$ value $<0.05)$ the positive effect in terms of propensity to donate generated by BeliefT. ${ }^{9}$

\subsection{Information effect (NoInfot vs InfoT)}

Providing information about past donations leads to a polarization of the donations in favor of ( 2 out of 3 ) the less endowed charities (Table 6; Fig. 2). The qualitative polarization of the categorical distribution of recipients is statistically significant according to Pearson $X^{2}$ test $(p$ value $<0.001) .{ }^{10}$ The nonparametric test rejects the

\footnotetext{
7 We call for simplicity non-donors those who choose not to donate to any of the listed organizations.

${ }^{8}$ Model (2) in Table 5 replicates the very same findings of Model (1), controlling for further demographics such as age, gender and education level.

${ }^{9}$ Computation: 0.0101 p.p. (Belief\&ThresholdT)—versus-0.0609 p.p.*** $($ BeliefT $)=-0.0508$ p.p.** (Threshold); Wald test $p$ value $=0.027$.

10 All statistically significant ( $p$ value $<0.01$ ) nonparametric tests are jointly significant at the $5 \%$ level based on Bonferroni-Holm stepwise multiple-hypotheses-testing procedure (Holm 1979). See Table 9 for the criterion cut-off $p$ values.
} 
Table 4 Descriptive statistics

\begin{tabular}{|c|c|c|c|c|c|c|}
\hline Variable & Definition & Obs & Mean & SD & Min & Max \\
\hline Emergency & $\begin{array}{l}\text { Percent of donors } \\
\text { selecting the } \\
\text { organization in the } \\
\text { tax donation choice }\end{array}$ & 1191 & 0.144 & 0.351 & 0 & 1 \\
\hline Unicef & & 1191 & 0.107 & 0.309 & 0 & 1 \\
\hline LAV & & 1191 & 0.049 & 0.215 & 0 & 1 \\
\hline WWF & & 1191 & 0.037 & 0.188 & 0 & 1 \\
\hline Greenpeace & & 1191 & 0.023 & 0.152 & 0 & 1 \\
\hline Amnesty & & 1191 & 0.044 & 0.204 & 0 & 1 \\
\hline Caritas & & 1191 & 0.236 & 0.425 & 0 & 1 \\
\hline Banco & & 1191 & 0.082 & 0.275 & 0 & 1 \\
\hline ADMO & & 1191 & 0.217 & 0.412 & 0 & 1 \\
\hline Non-donors & & 1191 & 0.061 & 0.239 & 0 & 1 \\
\hline Emergency (rank) & $\begin{array}{l}\text { Expected rank in } \\
\text { terms of aggregate } \\
\text { donations previous } \\
\text { year }\end{array}$ & 398 & 4.007 & 2.820 & 1 & 9 \\
\hline Unicef (rank) & & 398 & 3.907 & 2.516 & 1 & 9 \\
\hline Lav (rank) & & 398 & 6.439 & 2.184 & 1 & 9 \\
\hline Wwf (rank) & & 398 & 5.608 & 2.158 & 1 & 9 \\
\hline Greenpeace (rank) & & 398 & 5.638 & 2.243 & 1 & 9 \\
\hline Amnesty (rank) & & 398 & 4.927 & 2.131 & 1 & 9 \\
\hline Caritas (rank) & & 398 & 3.716 & 2.498 & 1 & 9 \\
\hline Banco (rank) & & 398 & 5.389 & 2.446 & 1 & 9 \\
\hline ADMO (rank) & & 398 & 5.319 & 2.755 & 1 & 9 \\
\hline \multicolumn{7}{|l|}{ Demographics } \\
\hline Gender & Female $=1$ & 1191 & 0.531 & 0.499 & 0 & 1 \\
\hline Age & & 1191 & 44.569 & 17.703 & 14 & 93 \\
\hline Education: middle school & & 1188 & 0.27 & -Share & 0 & 1 \\
\hline Education: high school & & 1188 & 0.64 & -Share & 0 & 1 \\
\hline Education: college level & & 1188 & 0.09 & -Share & 0 & 1 \\
\hline \multicolumn{7}{|l|}{ Marital status } \\
\hline Married & & 1191 & 0.436 & 0.496 & 0 & 1 \\
\hline Divorced/separated & & 1191 & 0.07 & 0.250 & 0 & 1 \\
\hline Widowed & & 1191 & 0.06 & 0.227 & 0 & 1 \\
\hline$\# N$ members & $\begin{array}{l}\text { Number of household } \\
\text { members }\end{array}$ & 1191 & 2.206 & 1.607 & 1 & 11 \\
\hline
\end{tabular}




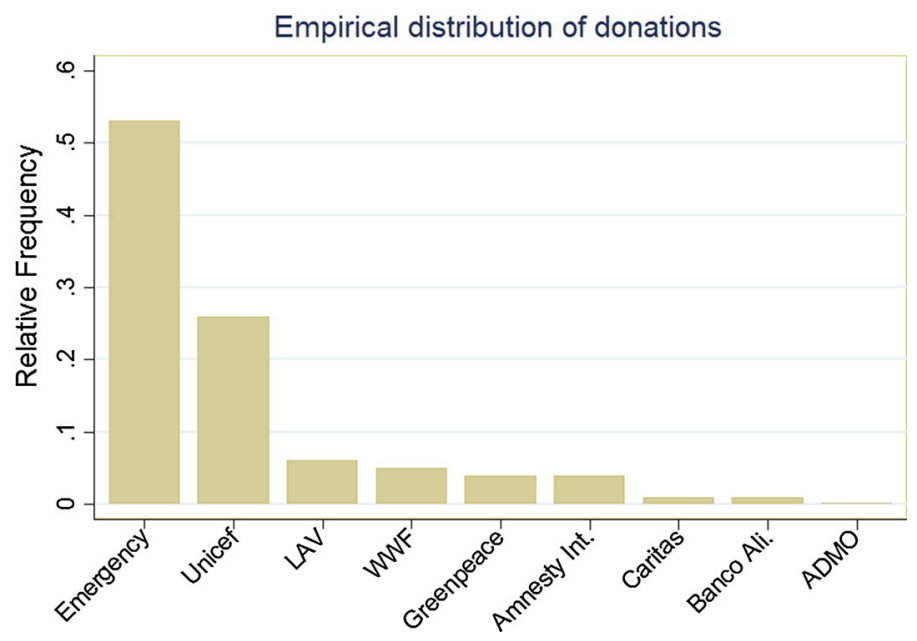

Fig. 1 Empirical distribution of donations (by charity)

Table 5 OLS linear probability model estimation

Dependent variable: Donation (dummy: 1 = donation, $0=$ no donation). Standard errors in parentheses. Age_cent = IndividualAge-AverageAge. In model (2) three observations are missing due to missing values in Edu. covariates

Significance levels:

$* * * p<0.01$; ** $p<0.05$;

$* p<0.1$
Variables

(1)

(2)

Donation

InfoT

BeliefT

$0.0699 * * *$

$0.0750 * * *$

(0.0193)

(0.0192)

Belief\&ThresholdT

$0.0609 * * *$

$0.0601 * * *$

(0.0169)

(0.0169)

0.0101

0.0175

(0.0230)

(0.0230)

Age_cent

0.000340

(0.000446)

Edu: High School

$0.0586 * * *$

(0.0161)

Edu: College

$0.0546 * *$

(0.0257)

0.0186

(0.0138)

Married

$0.0466 * * *$

(0.0156)

Constant

$0.902 * * *$

$0.849 * * *$

(0.0121)

(0.0167)

Observations

1,191

1,188

$R$-squared

0.017

0.039 


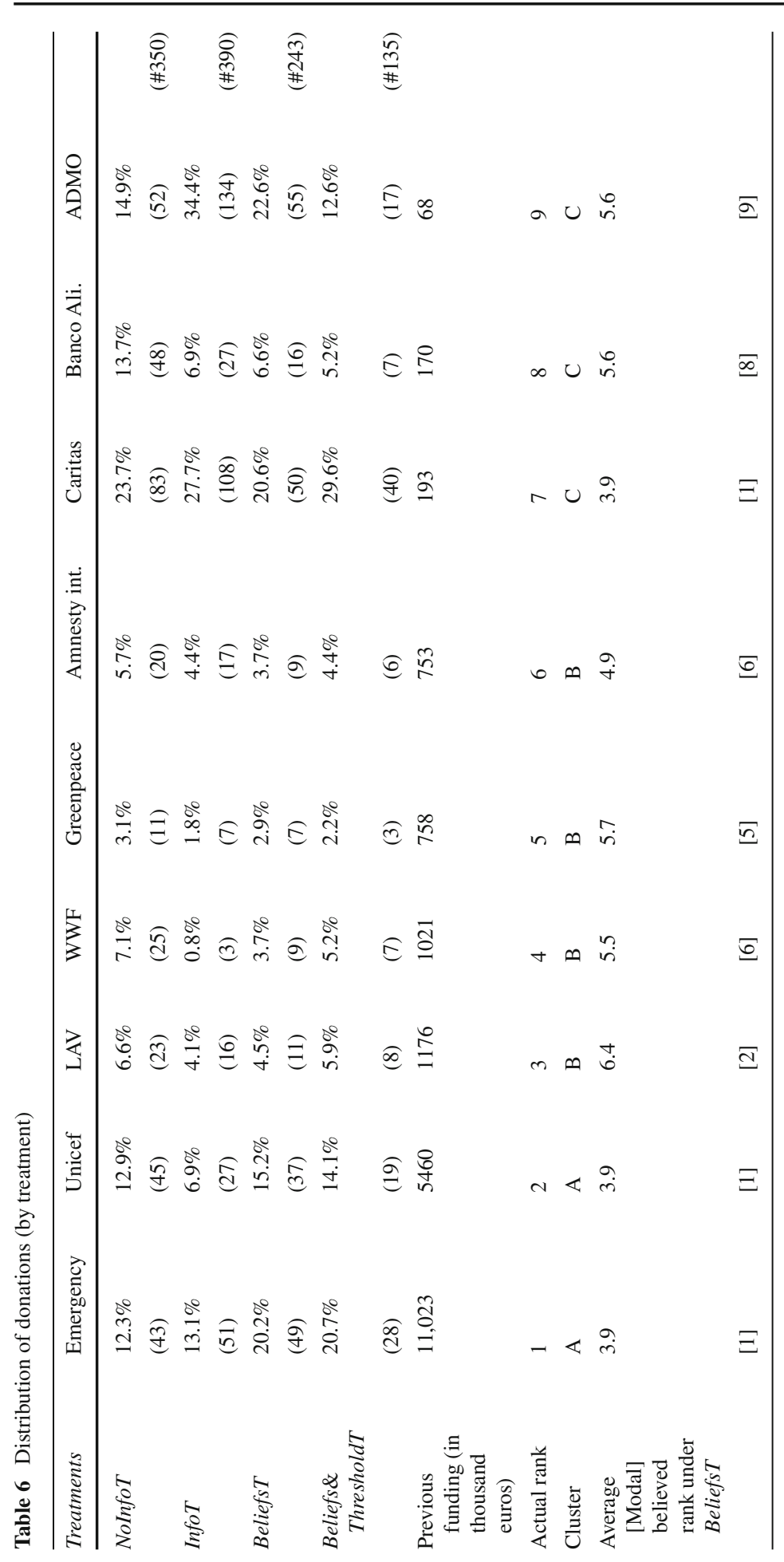




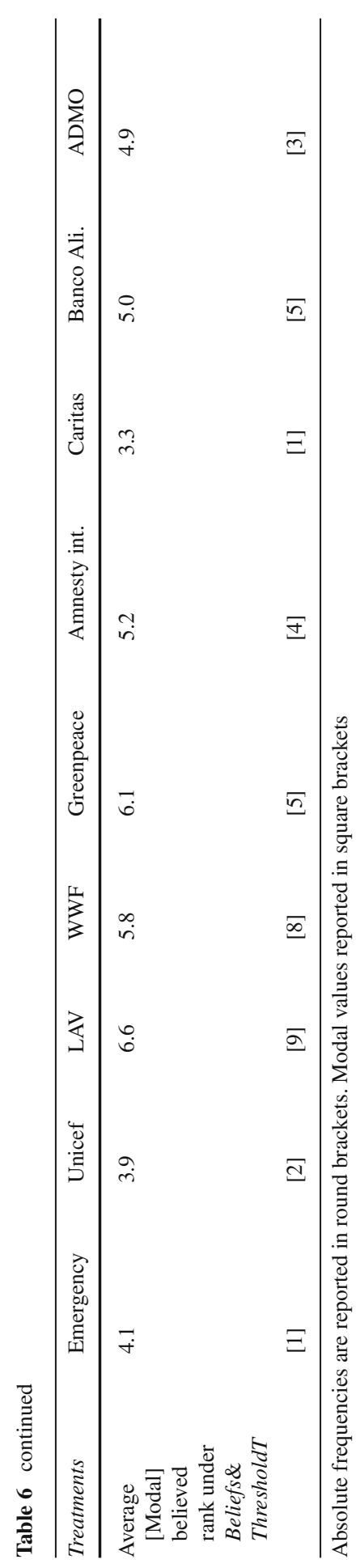



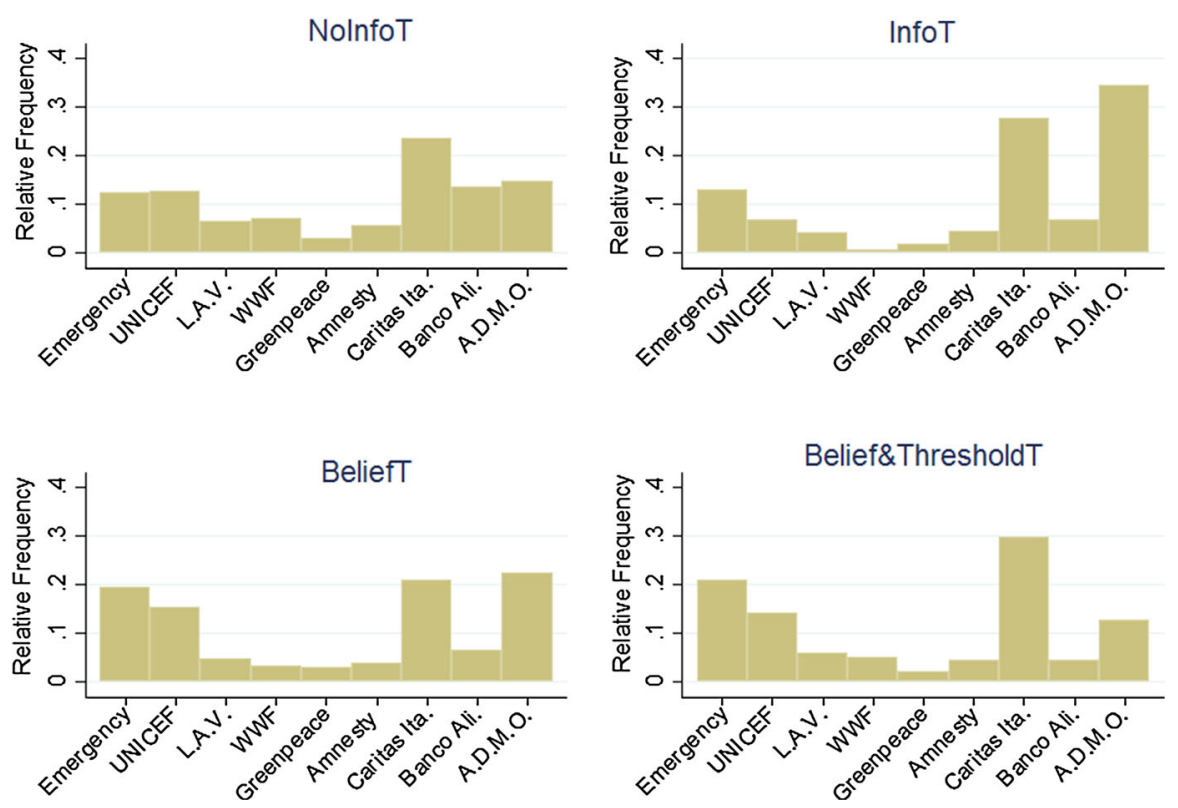

Fig. 2 Distribution of donations (by treatment)

null hypothesis of independence between experimental conditions and allocation of the donations to the different recipients. ${ }^{11}$

\subsection{The beliefs effect (NoInfoT vs BeliefT)}

In the BeliefT treatment, we ask participants to rank the organizations in terms of how much they believe each organization received the previous year. We do this to verify the effect of priming a comparative decision rule in the participants that could lead them, not only to focus on their preferred organization but also to think in terms of global distribution of funds. Besides we are also interested in studying whether beliefs are generally aligned with actual donations or systematically biased. This latter case, in fact, could explain any changes due to the provision of information.

We find that the belief elicitation procedure leads to a bipolarization of the donations with respect to the NoInfoT baseline case (Table 6; Fig. 2).

The bipolar $U$-shaped categorical distribution of recipients resulted by the introduction of the beliefs condition is statistically different from the distribution generated under the NoInfoT according to Pearson $X^{2}$ test ( $p$ value $=0.003$ ). The nonparametric test rejects the null hypothesis of independence between experimental conditions and donation allocations to the different recipients.

\footnotetext{
11 Results are even more self-evident if the different charities are clustered according to the volume of funding actually given during the previous 5x1000 wave (Table 8). Cluster A groups together the two major charities/outliers (Emergency and Unicef) that are able to attract a great volume of donations ( $>€ 5$ million each). Cluster B hosts organizations able to raise about $€ 1$ million each (LAV, WWF Greenpeace, Amnesty International). Cluster $\mathrm{C}$ is represented by three less endowed organizations (Caritas, Banco Alimentare, ADMO) collecting less than $€ 200.000$ each. Clustered analysis is presented in Appendix B.
} 
Table 7 "Beliefs-Donation" correlation

\begin{tabular}{lll}
\hline & Spearman correlation & $p$ values \\
\hline Organization_donation—rank1 & +0.39 & $<0.001$ \\
Organization_donation—rank2 & +0.09 & $=0.099$ \\
Organization_donation—rank3 & +0.05 & $>0.3$ \\
Organization_donation-rank4 & -0.01 & $>0.8$ \\
Organization_donation—rank5 & -0.1 & $=0.062$ \\
Organization_donation—rank6 & -0.13 & $=0.01$ \\
Organization_donation-rank7 & -0.06 & $>0.2$ \\
Organization_donation-rank8 & -0.14 & $=0.007$ \\
Organization_donation-rank9 & -0.18 & $<0.001$ \\
\hline
\end{tabular}

\subsubsection{Accuracy of beliefs and "beliefs-donation" correlation}

The degree of accuracy of the beliefs is very low: only $0.5 \%$ of the pool of subjects reported a ranking in line with the actual one; $2.4 \%$ of the subjects ranked correctly the top three organizations; 2.6 ranked correctly the three organizations in the middle range of the list (rank 4, 5, and 6); 4.7\% correctly identified the three organizations at the bottom of the list. Subjects tend to donate to the organization they rank first. This correlation is robust and statistically highly significant (Spearman correlation: +0.39 , $p$ value $<0.001)$ (Table 7).

Symmetrically, subjects tend to systematically avoid donations in favor of the charities they assign the lowest rank (Spearman correlation: $-0.18, p$ value $<0.001$ ). This "beliefs effect" goes in the opposite direction with respect to the "information effect." While under information treatment subjects tended to favor the less endowed organizations, under the beliefs treatment subjects granted generosity to the organizations that in their opinion are able to attract more donations.

\subsection{Threshold effect (BeliefT vs Belief\&ThresholdT).}

From the distributional perspective, the effect of the threshold rule does not imply major effects.

The categorical distribution of donations generated by Belief\&ThresholdT (Table 6; Fig. 2) is statistically indistinguishable compared to the one realized under BeliefT according to Pearson $X^{2}$ test ( $p$ value $>0.3 \mid$ tag:e).

\section{Conclusions}

In this paper, we report on a framed field experiment designed to study the effect, on people's charitable giving, of three, substantial and procedural, elements: information provision, belief elicitation and threshold on distribution. The study is framed within the 5 X1000 tax scheme, a mechanism actually available to Italian taxpayers, which 
allows them to allocate a small part of their taxes to a selected not-for-profit organization. The Italian law allows only a single choice option since it is not possible to allocate the amount to more than one organization. We replicate the scheme by asking a representative sample of the population to allocate a monetary prize to one among a list of well-known not-for-profit organizations. In order to mimic the tax donation scheme where there is no gain for the taxpayer in case of no choice, we consider a variant of the generosity game where the prize is not earned by the dictator in case she chooses not to donate. Based on these characteristics, our experimental design allows us to test three treatment variables associated with three different potential effects by: (i) providing information on the aggregate amount of donations received through the $5 X 1000$ channel by the listed organizations in the past year; (ii) eliciting participants' beliefs on the organization rank in terms of donations received in the past year; (iii) creating an upper bound on aggregate donations which imposes a proportional cut to contributions to each organization in case the aggregate threshold is passed (as it is in the actual 5X1000 mechanism).

We find two main sets of results: first on how information, beliefs elicitation and threshold affect the likelihood of giving. In this respect, the information effect is consistent with what we define the "complementarity effect." Knowing, in fact, how much others have donated in the recent past, the probability to donate increases significantly (6 percentage points). A similar effect is observed when before choosing players are asked to state their beliefs about how each organization ranks in terms of previous donations. Priming this comparative frame drives people to give even more (6 percentage points). A negative effect is, instead, associated with the imposition of a threshold to the maximum amount to be distributed. The threshold effect reduces participants' relative willingness to give by about 5 percentage points.

The second class of findings refers to the distributive effects. What is the impact of the treatment variables on the distribution of the donations? These are, we think, our main and more novel findings. If we consider donations that can alternatively target different organizations, we see that both information provision and belief elicitation exert a significant distributive effect: with respect to the baseline no-information treatment, when information is provided, participants tend to significantly lower their contributions to the top organizations and to be more generous with those at the bottom of the ranking. On the contrary, when beliefs are made salient the elicitation process leads to a statistically significant modification in the distribution. When asked to explicitly rank the organizations according to their beliefs about previous funding, participants give systematically to the organization they think is the best performer. Globally, this process leads to a distribution where the top performing organizations receive more and the worst performing organization slightly less. Finally, we find that the imposition of the threshold does not have any significant redistributive effects.

Objective information seems to work against people's expressed beliefs. In the first case, in fact, participants prefer to donate to the poorer organizations: it could be to maximize the marginal impact of their money or to foster pluralism and finance different forms of intervention. Disentangling the reasons behind such a behavior will be a subject for further research. We know, however, that when individuals' beliefs are made salient, these lead participants to concentrate their donation toward the best performers (with only two exceptions, Caritas and ADMO). We may speculate that 
the belief elicitation process could prime in the participants a comparative/competitive frame that tends to induce the participant to donate more frequently to the organization they rank first, producing, in this way, a sort of "St. Matthew effect"12 (Merton 1968; Salganik et al. 2006).

In concluding, we think that these findings, especially those related to the distributional effect, are novel and may have important policy implications, both in general and more specifically to the 5X1000 mechanism. The introduction of a threshold for the total amount to be distributed, for example, if on the one hand reduces the State's expenditure, at the same time, could crowd-out private donations, leading to an underfinancing of the not-for-profit sector.

If one, instead, wants to encourage donations and foster pluralism, the social information effect could be an effective tool of behavior change, both at the public level but also for each organization. Especially, the poorer ones may want to let the prospective donors know about the funds collected by their richer competitors. This could, in fact, favor redistribution to their advantage.

Acknowledgements We thank Maria Bigoni, Federico Revelli, Rainer Michael Rilke, Matteo Rizzolli, Robert Sudgen, Daniel Zizzo and an anonymous referee for helpful comments on a previous version of the paper, as well as the participants to the Behavioral Science and Policy-Network for the Integrated Behavioral Science Annual Conference, Nottingham, 21-23/04/2015. Financial support from CSV-Sardegna Solidale is gratefully acknowledged.

\section{Appendix A: Instructions}

\section{General instructions}

Sardegna Solidale and the University of Cagliari are grateful for your decision to participate to this research. We ask you to fill the following questionnaire in all its parts. Try to answer autonomously to all questions and, in case of necessity, ask for the support of our researcher. Answers will be evaluated by us in anonymous form and elaborated in aggregate. Researchers will not be able in any case to retrieve the respondent's identity.

\section{The choice questionnaire task}

By filling this questionnaire, you will take part in a lottery organized by the Department of Economics and Business of the University of Cagliari. The drawn will take place on the 31 st of October 2013, one all the questionnaires will be collected. The winner's identity will be kept anonymous to the researchers and she/he will be contacted by the Sardegna Solidale volunteers by means of the numeric code you received.

The first and unique prize is equal to $€ 1000$. However, this money will not go to the winner. She/he can decide whether to give it or not to one charitable organization

\footnotetext{
12 "For unto every one that [we believe] hath shall be given, and he shall have abundance: but from him that [we believe] hath not shall be taken even that which he hath" (Matthew 25:29, King James Version).
} 
among those from the list below. If the prize is not given the winner will not receive anything anyway.

Now we ask you to imagine that you have already won the prize. You now have $€$ 1000 that you could give or not to give to one among the not-for-profit organization listed below.

If after the drawn you will result as the lottery winner, the decision you are about to make will be implemented for real. That means that if you decided to give to some organization the prize, such an organization will receive the money for real, otherwise, if you decided not to give, the prize will not be distributed.

\section{(In the no-info treatment)}

Tick $\square$ the box corresponding to your choice:

\begin{tabular}{ll}
\hline Tick your preferred option & Organizations \\
\hline$\square$ & NO DONATION \\
$\square$ & EMERGENCY \\
$\square$ & UNICEF - ITALIA \\
$\square$ & L.A.V._LEGA ANTIVIVISEZIONE \\
$\square$ & WWF_WORLD WIDE FOUNDATION ITALIA \\
$\square$ & GREENPEACE \\
$\square$ & AMNESTY INTERNATIONAL - SEZIONE ITALIANA \\
$\square$ & CARITAS ITALIANA \\
$\square$ & BANCO ALIMENTARE ONLUS \\
$\square$ & ADMO_ASSOCIAZIONE DONATORI MIDOLLO OSSEO \\
\hline
\end{tabular}

\section{(In the info treatment)}

Tick $\square$ the box corresponding to your choice:

\begin{tabular}{lll}
\hline $\begin{array}{l}\text { Tick your pre- } \\
\text { ferred option }\end{array}$ & Organizations & $\begin{array}{l}\text { Funding } \\
\text { Received in } \\
2011 \text { through } \\
5 \times 1000(€)\end{array}$ \\
\hline$\square$ & - \\
$\square$ & & $11,023,415.00$ \\
$\square$ & NO DONATION & $5,460,307.00$ \\
$\square$ & EMERGENCY & $1,176,578.00$ \\
$\square$ & UNICEF_ITALIA & $1,021,070.00$ \\
$\square$ & L.A.V._LEGA ANTIVIVISEZIONE & $758,835.00$ \\
$\square$ & WWF_WORLD WIDE FOUNDATION ITALIA & $753,674.00$ \\
$\square$ & GREENPEACE & $193,890.00$ \\
$\square$ & AMNESTY INTERNATIONAL_SEZIONE ITALIANA & $170,351.00$ \\
$\square$ & CARITAS ITALIANA & $68,828.00$ \\
\hline
\end{tabular}




\section{(In the no-info+beliefs elicitation treatment)}

Before making your choice we ask you to order (by assigning a specific rank) each organization in terms of how much funding you think they received the previous year through the $5 \times 1000$ mechanism (denote with 1 the organization that raised more money and with 9 the one that raised less and with all the other numbers 2-8 those in the intermediate positions)

Tick $\nabla$ the box corresponding to your choice:

\begin{tabular}{lll}
\hline $\begin{array}{l}\text { Tick your pre- } \\
\text { ferred option }\end{array}$ & Organizations & $\begin{array}{l}\text { Ranking Indicate the position of each } \\
\text { organization in term of funding received } \\
\text { latest year }(1=\text { first... } 9=\text { last })\end{array}$ \\
\hline$\square$ & - \\
$\square$ & NO DONATION & \\
$\square$ & EMERGENCY & \\
$\square$ & UNICEF_ITALIA & \\
$\square$ & L.A.V. _LEGA ANTIVIVISEZIONE \\
$\square$ & WWF_ WORLD WIDE \\
$\square$ & FOUNDATION ITALIA \\
$\square$ & GREENPEACE \\
$\square$ & AMNESTY INTERNATIONAL - \\
$\square$ & SEZIONE ITALIANA \\
& CARITAS ITALIANA \\
\hline
\end{tabular}

\section{(In the no-info+beliefs elicitation + threshold treatment)}

Before making your choice we ask you to order (by assigning a specific rank) each organization in terms of how much funding you think they received the previous year through the 5X1000 mechanism (denote with 1 the organization that raised more money and with 9 the one that raised less and with all the other numbers $2-8$ those in the intermediate positions)

Note that if the amount of the aggregate donations is greater than a given threshold, only a fraction of the $€ 1000$ will be actually distributed to the organization.

Tick $\nabla$ the box corresponding to your choice: 


\begin{tabular}{lll}
\hline $\begin{array}{l}\text { Tick your pre- } \\
\text { ferred option }\end{array}$ & Organizations & $\begin{array}{l}\text { Ranking Indicate the position of each } \\
\text { organization in term of funding received } \\
\text { latest year }(1=\text { first...9 = last })\end{array}$ \\
\hline$\square$ & - \\
$\square$ & NO DONATION \\
$\square$ & EMERGENCY \\
$\square$ & UNICEF-ITALIA & \\
$\square$ & L.A.V._LEGA ANTIVIVISEZIONE \\
$\square$ & WWF _ WORLD WIDE FOUNDA- \\
$\square$ & TION ITALIA \\
$\square$ & GREENPEACE \\
$\square$ & AMNESTY INTERNATIONAL - \\
$\square$ & SEZIONE ITALIANA \\
& CARITAS ITALIANA \\
\hline & BANCO ALIMENTARE ONLUS \\
\hline
\end{tabular}

\section{Appendix B: Clustered analysis}

\section{B.1 Information effect (NoInfot vs InfoT)—Sect. 3.2}

Information provision leads donors to act systematically more in favor (with respect to the no information treatment) of the less endowed charities of cluster $\mathrm{C}$.

The main result is confirmed also in this alternative clustered setting (see Table 8; Fig. 3). The categorical distribution of recipients under InfoT is contrasted against the NoInfoT distribution. Donations density moves from cluster A ( -5 percentage points) and $\mathrm{B}(-11$ percentage points) in favor of cluster C's charities (+16 percentage points). This qualitative polarization of the donation behavior results to be highly statistically significant according to Pearson $X^{2}$ test ( $p$ value $<0.001 \mid$ tag $: \mathrm{b}$ ).

Table 8 Donations received by each of the nine organizations in the previous fiscal year through the 5X1000 mechanism

\begin{tabular}{lcc}
\hline Charity & Donations received & Cluster \\
\hline Emergency & $11,023,415.00$ & $\mathrm{~A}$ \\
Unicef_-Italia & $5,460,307.00$ & $\mathrm{~A}$ \\
L.A.V._Lega Antivivisezione & $1,176,578.00$ & $\mathrm{~B}$ \\
WWF_World Wide Foundation Italia & $1,021,070.00$ & $\mathrm{~B}$ \\
Greenpeace & $758,835.00$ & $\mathrm{~B}$ \\
Amnesty International—Sezione Italiana & $753,674.00$ & $\mathrm{~B}$ \\
Caritas Italiana & $193,890.00$ & $\mathrm{C}$ \\
Banco Alimentare Onlus & $170,351.00$ & $\mathrm{C}$ \\
ADMO_Associazione Donatori Midollo Osseo & $68,828.00$ & $\mathrm{C}$ \\
\hline
\end{tabular}



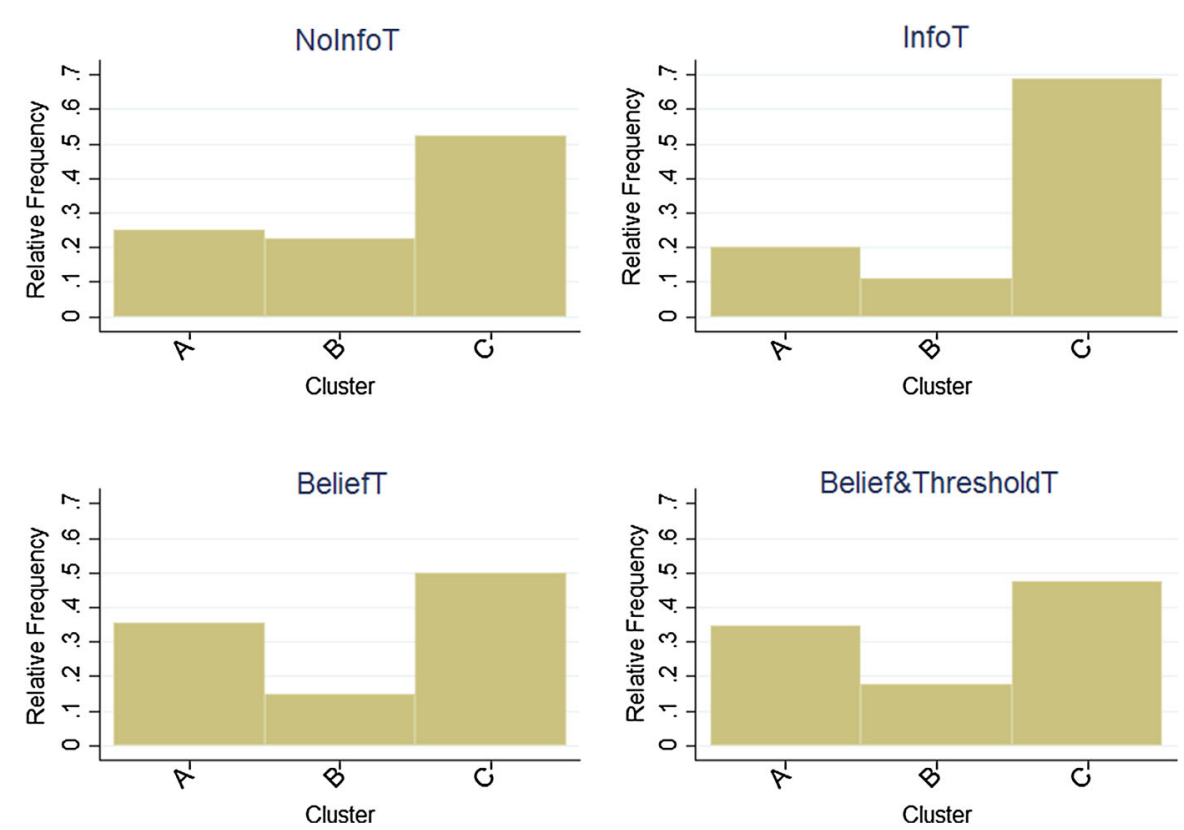

Fig. 3 Distribution of donations (by treatment)—clustered

\section{B.2 The beliefs effect (NoInfoT vs BeliefT)-Sect. 3.3}

Also in this case, the analysis at cluster level helps to better highlight the underling dynamic (Table 8; Fig. 3). Visual inspection of Fig. 3. suggests how the $U$-shaping effect is mainly driven by an increase of donations in favor of better endowed charities belonging to cluster $\mathrm{A}(+10$ percentage points) and a correspondent decrease of donations to the less endowed ones of cluster B ( -8 percentage points) and $C(-2$ percentage points). As for the previous test, also in this further clustered configuration the Pearson $X^{2}$ test rejects ( $p$ value $=0.008 \mid$ tag $: \mathrm{d}$ ) the null hypothesis of independence between experimental conditions and donation allocations to the clustered recipients.

\section{B.3 Threshold effect (BeliefT vs Belief\&ThresholdT)—Sect. 3.4}

The same result holds true when the clustered categorization is considered. Visual inspection of Fig. 3 (see also Table 8) confirms how the two clustered categorical distributions display analogous patterns of donations by treatments (cluster $\mathrm{A} \approx 35 \%$; cluster $\mathrm{B} \approx 16.5 \%$; cluster $\mathrm{C} \approx 48.5 \%$ ). The Pearson $X^{2}$ test fails to reject ( $p$ value $>$ $0.7 \mid$ tag: $f$ ) the null hypothesis of independence between experimental conditions and donation allocations to the clustered recipients (Tables 9, 10). 
Table 9 Bonferroni-Holm stepwise multiple-hypotheses-testing procedure (Holm 1979)

\begin{tabular}{llllll}
\hline Rank & $p$ value & Tag: test & \multicolumn{2}{l}{ Criterion cut-off $p$ values } & Level 1\% \\
\cline { 3 - 5 } & & & Level 10\% & Level 5\% & Level \\
\hline 1 & 0.7 & {$[\mathrm{f}]$} & 0.1 & 0.05 & 0.01 \\
2 & 0.3 & {$[\mathrm{e}]$} & 0.05 & 0.025 & 0.005 \\
3 & 0.008 & {$[\mathrm{~d}]$} & 0.033 & 0.017 & 0.003 \\
4 & 0.003 & {$[\mathrm{c}]$} & 0.025 & 0.013 & 0.003 \\
5 & $<0.001$ & {$[\mathrm{a}]$} & 0.02 & 0.01 & 0.002 \\
6 & $<0.001$ & {$[\mathrm{~b}]$} & 0.017 & 0.008 & 0.002 \\
\hline
\end{tabular}

Table 10 Distribution of donations (by information, belief elicitation and threshold)—clustered

\begin{tabular}{lllll}
\hline & Cluster A & Cluster B & Cluster C & \\
\hline NoInfoT & $25.1 \%$ & $22.6 \%$ & $52.3 \%$ & $(183)$ \\
& $(88)$ & $(79)$ & $69 \%$ & (\#350) \\
InfoT & $20 \%$ & $11 \%$ & $(269)$ & \\
& $(78)$ & $(43)$ & $49.8 \%$ & $(\# 390)$ \\
BeliefsT & $35.4 \%$ & $14.8 \%$ & $(121)$ & \\
& $(89)$ & $(36)$ & $47.4 \%$ & $(\# 243)$ \\
Beliefs\&ThesholdT & $35.4 \%$ & $17.2 \%$ & $(64)$ & $(\# 135)$ \\
& $(47)$ & $(24)$ & &
\end{tabular}

Absolute frequencies are reported in round brackets

\section{References}

Andreoni, J. (1988). Privately provided public goods in a large economy: The limits of altruism. Journal of Public Economics, 35(1), 57-73.

Andreoni, J. (1990). Impure altruism and donations to public goods: A theory of warm glow giving. Economic Journal, 100(401), 464-477.

Andreoni, J. (2006). Philanthropy. In S.-C. Kolm \& J. M. Ythier (Eds.), Handbook of giving, reciprocity and altruism (pp. 1201-1269). Amsterdam: North Holland.

Andreoni, J., \& Bernheim, D. (2009). Social image and the 50-50 norm: A theoretical and experimental analysis of audience effects. Econometrica, 77(5), 1607-1636.

Becker, G. S. (1974). A theory of social interactions. Journal of Political Economy, 82, 1064-93.

Benabou, R., \& Tirole, J. (2006). Incentives and prosocial behavior. American Economic Review, 96(5), 1652-1678.

Bernheim, D. (1994). A theory of conformity. Journal of Political Economy, 102(5), 841-877.

Cialdini, R. (1984). Influence, the psychology of persuasion. New York: Harper Collins.

Cialdini, R. B., \& Goldstein, N. J. (2004). Social influence: Compliance and conformity. Annual Review of Psychology, 55, 591-622.

Ellingsen, T., \& Johannesson, M. (2007). Paying respect. Journal of Economic Perspectives, 21(4), 135-49.

Ellingsen, T., \& Johannesson, M. (2008). Pride and prejudice: The human side of incentive theory. American Economic Review, 98(3), 990-1008.

Falk, A., \& Zimmermann, F. (2013). A taste for consistency and survey response behavior. CESifo Economic Studies, 59(1), 181-193.

Fong, C., \& Luttmer, E. (2011). Do race and fairness matter in generosity? Evidence from a nationally representative charity experiment. Journal of Public Economics, 95(5-6), 372-394. 
Frey, B. S., \& Meier, S. (2004). Pro-social behavior in a natural setting. Journal of Economic Behavior and Organization, 54, 65-88.

Güth, W. (2010). The generosity game and calibration of inequity aversion. Journal of Socio-Economics, 39, 155-157.

Güth, W., Levati, M. V., \& Ploner, M. (2012). An experimental study of the generosity game. Theory and Decision, 72(1), 51-63.

Holm, S. (1979). A simple sequentially rejective multiple test procedure. Scandinavian Journal of Statistics, 6(2), 65-70.

Kolm, S. C., \& Ythier, J. M. (2006). Handbook of giving and reciprocity and altruism. Amsterdam: North Holland.

Merton, R. K. (1968). The Matthew effect in science. Science, 159(3810), 56-63.

Johansson-Stenman, O., \& Svedsater, H. (2008). Measuring hypothetical bias in choice experiments: The importance of cognitive consistency. The B.E. Journal of Economic Analysis and Policy, 8(1), Article 41.

Pelligra, V., \& Stanca, L. (2013). To give or not to give? Equity, efficiency and altruistic behavior in an artefactual field experiment. Journal of Socio-Economics, 46, 1-9.

Penner, L. A., Dovidio, J. F., Piliavin, J. A., \& Schroeder, D. A. (2005). Prosocial behaviour: Multilevel perspectives. Annual Review of Psychology, 56, 365-92.

Powell, W., \& Steinberg, R. (2006). The nonprofit sector: A research handbook. New Haven, CT: Yale University Press.

Roberts, R. (1984). A positive model of private charity and public transfers. Journal of Political Economy, 92(1), 136-148.

Salganik, M., Dodds, P., \& Watts, D. (2006). Experimental study of inequality and unpredictability in an artificial cultural market. Science, 311, 854-856.

Scharf, K. (2014). Private provision of public goods and information diffusion in social groups. International Economic Review, 55, 1019-1042.

Shang, J., \& Croson, R. (2009). A field experiment in charitable contribution: The impact of social information on the voluntary provision of public goods. Economic Journal, 119(540), 1422-1439.

Sugden, R. (1984). Reciprocity: The supply of public goods through voluntary contributions. Economic Journal, 94, 772-87.

Vesterlund, L. (2003). The informational value of sequential fundraising. Journal of Public Economics, 87(3), 627-657.

Vesterlund, L. (2006). Why do people give? In R. Steinberg \& W. Powell (Eds.), The nonprofit sector (2nd ed.). New Heaven: Yale Press.

Warr, P. (1982). Pareto optimal redistribution and private charity. Journal of Public Economics, 19(1), 131-138.

Weber, J. M., Kopelman, S., \& Messick, D. M. (2004). A conceptual review of decision making in social dilemmas: Applying a logic of appropriateness. Personality and Social Psychology Review, 8(3), 281-307.

Yariv, L. (2005). I'll see it when I believe it: A simple model of cognitive consistency. Working paper, Department of Economics, UCLA. http://people.hss.caltech.edu/ lyariv/papers/Believe.pdf. 